\title{
STUDYING THE PROCESS OF DISSIPATION OF ENERGY OF MOTION IN HIGHLY FRACTURED GLACIERS USING REMOTE-SENSING TECHNIQUES (Abstract)
}

by

\author{
A.B. Kazanskiy
}

(Institute of Geography, U.S.S.R. Academy of Sciences, Staromonetny 29, Moscow 109017, U.S.S.R.)

\begin{abstract}
New aspects of the physics of ice movement in glaciers are presented. An analysis of the equation for the energy of a moving ice mass shows that the energy which is dissipated into heat (internal friction in a glacier) occurs not only because of average ice-velocity profiles, as it is commonly considered when simulating glaciers by continuum laminar flow. It also turns out that a significant part of the internal friction is associated with the dissipation of motion energy on internal macroheterogeneities in a glacier: at places where fractures appear and, in the case of a block structure, at points of contact between individual blocks, on ice dams, ice bridges, etc. This mechanism seems to be dominant during rapid ice flow in highly fractured glaciers.

The process was previously examined on the surging Medvezhiy Glacier in the central Pamir Mountains. On Medvezhiy Glacier the above phenomenon was particularly distinctive because of anomalously high ice-movement velocities during a calm period; that is, between consecutive surges (ice velocity amounted to $3-5 \mathrm{~m} \mathrm{~d}^{-1}$ ) and because of the block structure of the glacier against the background of its fracturing. Simple measurements of "instant" velocities of a large number of bench marks on the glacier surface, located across the middle flow course of the glacier, established that velocities at all points are of a fluctuating character, which outwardly resemble velocity fluctuations seen in turbulent liquid flow. It turns out that deviations of the "instant" velocity from the average velocity can amount
\end{abstract}

to more than $50 \%$ of the latter. Using data obtained from periodic recordings of the "instant" velocity for fixed pairs of bench marks, which were located at different distances (so that it was possible to evaluate the difference in instant velocities), a structural function was constructed. This structural function meets the well-known, so-called Kholmogorov two-thirds law for local isotropic turbulence. This indicates that, as with turbulence, the energy of middle movement is transferred along a cascade of ice conglomerates of decreasing size down to the smallest, limited only by the dimensions of fundamental blocks. At the points of contact at dams and junctions, motion energy dissipates into heat. It is postulated that this phenomenon may have a much broader application; it may also be characteristic of the movement of any fractured mass of solid material.

These findings may be used to formulate a theory which describes the mechanism of auto-oscillations in a surging glacier. According to this theory, the pseudoturbulent character of internal friction during a quiescent period (between surges) is one of the factors which prevents the appearance of a surge as long as possible, thus ensuring the growth of a new active glacier after each ice catastrophe.

These studies also conclude research on the general concept of auto-oscillations of mountain glaciers - the socalled surging glaciers, originally formulated in the course of research on the cause of a surge on Medvezhiy Glacier in 1963. This concept was subsequently adopted and is now widely used in glaciology.

\section{CALCULATION OF MASS BALANCE OF GLACIERS BY REMOTE-SENSING IMAGERY USING SIMILARITY OF ACCUMULATION AND ABLATION ISOLINE PATTERNS}

\author{
(Abstract) \\ A.N. Krenke and V.M. Menshutin \\ (Institute of Geography, U.S.S.R. Academy of Sciences, Staromonetny 29, Moscow 109017, U.S.S.R.)
}

\section{ABSTRACT}

A number of maps of component isolines of the Maruch Glacier's (West Caucasus) mass balance compiled on the basis of field observations during 11 years were analyzed.

The total balance of the glacier's mass seems to be closely associated with the relationship between accumulation and ablation areas by years, while the total values of net accumulation and ablation are fully determined by the surface-area values of accumulation and ablation regions. The layer of residual snow in the nourishment area by the end of the ablation season and the layer of many-year ice melting in the discharge area changes from year to year against the points fixed in space, but their mean specific value according to the above glaciological areas remains constant from year to year.

Using the results and the remote-sensing images, in which the many-year ice and the snow surplus are well distinguished, it is possible to estimate the areas of the ablation and accumulation regions for the studied glacier and then the mass balance, net accumulation, and, naturally, the run-off from the melting many-year ice.

Estimation of the distribution within the glacier of not only "net" but also total values of accumulation and ablation is possible, if this distribution is similar from year to year, and if total values of accumulation and ablation are known at certain points. The multitude of points, for which total accumulation and ablation may be determined by remote-sensing images, is found on the equilibrium line or on the transient snow line of the glacier at any date during the ablation season. In the first instance, ablation and accumulation, the latter being here equal to the former by definition, may be calculated by the mean summer temperature of the air, extrapolated for the corresponding altitude against the nearest meteorological station. Secondly, ablation is calculated by the sum of positive temperatures of the air and by the temperature coefficient of snow melting, extrapolated for the altitude of the transient snow line. 
In order to check the hypothesis of the similarity of isoline systems for accumulation and ablation, all the final values for each year and measured at different points have been normalized according to their mean value for each year.

The normalized maps turned out to be similar to each other. Using the regular net of points, we calculated the variation coefficient of normalized values. They were smaller by 0.20 for the whole area of the maps of normalized ablation and for the greater part of the map area of normalized accumulation. A map of mean normalized values was compiled for 11 years. The isoline "unit" on it coincided with the many-year firn line. With the help of this topological map, one can compile maps for distribution of ablation and accumulation on a glacier for any year or moment, for which there are data on the location of the nourishment line or snow line according to a remote-sensing image and for which air temperature at the altitude of these lines may be estimated.

In conclusion, the degree of similarity of the maps of component isolines for the glacier mass balance between different glaciers of the same morphological type was analyzed. For this, we used normalization of not only the characteristics of the glaciers' mass balances but also of morphological characteristics (altitudinal change, width, etc.). The results point to similarity of distribution of accumulation and ablation among glaciers. This will allow us to extrapolate the principal features of the isoline maps and the described methods of calculation from the studied glaciers to unexplored ones.

\title{
SATELLITE-ALTIMETER MEASUREMENTS OF SURFACE HEIGHT IN SEA-ICE AREAS
}

\section{(Abstract)}

\author{
by
}

S.W. Laxon and C.G. Rapley

(Mullard Space Science Laboratory, University College London, Dorking, Surrey RH5 6NT, U.K.)

\section{ABSTRACT}

The Seasat radar altimeter was designed to operate over the open ocean and encountered problems over sea ice. In particular, the on-board measurements of surface height were noisy and unreliable. As a consequence, published mean sea-surface and geoid maps based on the Seasat on-board height estimates either omit sea-ice-covered areas or include suspect data. We have identified and investigated the problems encountered by the Seasat altimeter over sea ice and have developed a technique for extracting accurate surface-height values from the sea-ice echo wave-form data. The retracking method is based upon fitting real wave forms to a library of model returns.

\section{CHARACTERISTICS OF ALTIMETRY SIGNATURES OVER SEA ICE}

\section{(Abstract)}

\author{
by
}

N.F. McIntyre and S.W. Laxon

(Mullard Space Science Laboratory, University College London, Dorking, Surrey RH5 6NT, U.K.)

\begin{abstract}
We report characteristics of Seasat altimetry signatures recorded over Antarctic sea ice. Up to four discrete zones can at times be seen in characteristic sequences in the Weddell and Ross Seas, and elsewhere. They are substantially larger than those reported in the Arctic, covering up to $2500 \mathrm{~km}$ at the time of maximum ice extent in 1978 . Transitions between them can be abrupt, with marked changes occurring in less than a few kilometres. Some zones were found to persist through the 3 month satellite lifetime; others exhibited intermittent variations. Repeat data coverage has enabled temporal as well as spatial patterns to be investigated.
\end{abstract}

Interpretation of the geophysical cause of the patterns observed has been limited by available data. Some comparisons may be made with surface measurements of nadir back-scatter on first- and multi-year floes but these account for only a small proportion of the altimetry returns studied. Correlations with the NOAA Navy Ice Charts show significant disparities in the determination of the ice edge which may relate to the sensitivity of the altimeter to the presence of fresh ice or ice in very small quantities. Similar signatures can be found next to small coastal leads at the continental margin, an area known to be important for the growth of new ice. 